\title{
Doença de Parkinson no Contexto da Pandemia COVID-19
}

\section{Parkinson Disease in the Context of the COVID-19 Pandemics}

\author{
Rita M Simões ${ }^{1,2}$, José Vale 1 ,3.* \\ 1-Serviço de Neurologia, Hospital Beatriz Ângelo, Loures, Portugal. \\ 2-Campus Neurológico Sénior, Torres Vedras, Portugal. \\ 3-Hospital dos Lusíadas, Lisboa, Portugal.
}

\section{Introdução}

Embora a infeção pelo coronavírus SARS-CoV-2 (severe acute respiratory syndrome coronavirus 2), também conhecida por COVID-19, seja essencialmente uma doença respiratória, a sua expressão pandémica e a gravidade das suas manifestações têm implicações importantes em muitos doentes com patologia neurológica. Têm também sido descritos casos de envolvimento neurológico pela própria doença.

No que respeita à doença de Parkinson (DP) existe ainda pouca informação, quer sobre o risco de infeção por SARS-CoV-2, quer sobre o comportamento da DP nos doentes infetados. Relativamente ao tratamento e a potenciais interações medicamentosas com fármacos de ação antiviral, os dados disponíveis são escassos e em grande parte especulativos.

Em seguida resumem-se os conhecimentos e hipóteses discutidas até à data sobre a interação bidirecional entre a DP (como protótipo das restantes doenças do movimento) e a infeção COVID-19.

\section{Risco de infeção pelo coronavírus SARS-CoV-2 nos doentes com DP \\ Vulnerabilidade dos DP para contrair a infeção e desenvolver doença mais grave}

É consensual que a DP, por si só, não confere um risco acrescido para contrair a infeção. Todavia, importa ter em conta que o risco de doença grave e a mortalidade aumentam significativamente a partir dos 65-70 anos e quando existem outras comorbilidades médicas (hipertensão arterial, doença cardiovascular, diabetes mellitus e doença renal).' Para além disso, é compreensível que a existência de dificuldades ventilatórias relacionadas com a DP coloquem estes doentes numa situação de maior vulnerabilidade para doença severa.

É admitido que alguns medicamentos usados na DP, nomeadamente a amantadina, a memantina, e eventualmente a safinamida, possam conferir um efeito protetor contra a infeção e as suas consequências. ${ }^{2}$ Esta hipótese pressupõe que a inibição da atividade dos recetores NMDA do glutamato pode diminuir a excitotoxicidade neuronal e os efeitos nefastos da inflamação. Por outro lado, a amantadina e a memantina são ambos derivados do adamantano, que tem propriedades antivirais. A amantadina tem atividade antiviral demonstrada em modelos animais contra o vírus influenza $A .{ }^{3}$ Um derivado do adamantano - bananina - inibe a helicase do SARS-CoV impedindo a replicação viral, ${ }^{3}$ efeito esse que pode ser também hipoteticamente atribuído à amantadina e memantina.
Informações/Informations: Artigo de perspetiva,

publicado em Sinapse, Volume 20, Número 2, abril-junho 2020. Versão eletrónica em www.sinapse.pt

Perspective article, published in Sinapse, Volume 20, Number 2, april-june 2020. Electronic version in www.sinapse.pt

(C) Autor (es) (ou seu (s) empregador (es)) 2020. Reutilização permitida de acordo com CC BY-NC. Nenhuma reutilização comercial.

(C) Author(s) (or their employer(s)) 2020. Re-use permitted under CC BY-NC. No commercial re-use.

Palavras-chave:

Doença de Parkinson:

SARS-CoV-2;

COVID-19.

Keywords: Parkinson Disease SARS-CoV-2;

COVID-19.

*Autor Correspondente / Corresponding Author: José Vale

Serviço de Neurologia Hospital Beatriz Ângelo

Av. Carlos Teixeira, $n^{\circ} 3$ 2674-514 Loures, Portugal josevale.neuro@gmail.com

Recebido / Received: 2020-05-03 Aceite / Accepted: 2020-06-28 Publicado / Published: 2020-07-13

DOI: https://doi.org/10.46531/ sinapse/AP/ COVID19/ValeJ/2020

\section{Vulnerabilidade da DP para outras complicações durante a infeção COVID-19}

A medicação dopaminérgica usada na DP, nomeadamente levodopa, inibidores da monoaminoxidase $\mathrm{B}$, inibidores da catecol-O-metiltransferase, agonistas dopaminérgicos e amantadina, são seguros a este nível e não é expectável a ocorrência de interações medicamentosas com os fármacos que têm vindo a ser usados no tratamento da COVID-19. Esta medicação deve ser mantida duran- 
te a infeção e, se for o caso, durante o internamento, de forma a reduzir o risco de complicações hospitalares.

Por outro lado, alguns medicamentos com benefício demonstrado na minimização das formas severas da COVID-19, incluem fármacos que prolongam o intervalo QT, podendo causar complicações cardíacas graves (cloroquina, hidroxicloroquina e azitromicina). Este facto assume maior relevância nos doentes com DP que estejam medicados por sintomas não motores com fármacos que podem também prolongar o intervalo QT, como a domperidona, os antidepressivos e os neurolépticos. De resto, nas fases mais avançadas da DP é mais frequente a presença de intervalos QT prolongados, achado que se tem atribuído à disfunção autonómica. ${ }^{4}$

\section{Papel da infeção pelo coronavírus SARS-CoV-2 no desenvolvimento e na evolução da DP Efeitos diretos do SARS-CoV-2}

Desde o seu aparecimento tem vindo a ser discutido o potencial neurotropismo do SARS-CoV-2 e as suas eventuais implicações clínicas, quer no contexto da infeção aguda quer a longo prazo. Têm sido descritas alterações neurológicas em cerca de um terço dos doentes infetados, durante a fase aguda, sobretudo nos que têm doença mais grave, e que incluem cefaleia, depressão do estado de consciência e parestesias. ${ }^{5}$ Desconhece-se contudo, se estas manifestações traduzem uma ação direta do vírus no sistema nervoso central (SNC) ou se são secundárias aos efeitos locais ou sistémicos da doença. No entanto, outros coronavírus humanos, como o SARS-CoV e o MERS-CoV, têm capacidade demonstrada de invadir o SNC, tendo a experimentação em ratinhos indicado que esta invasão pode ocorrer através dos nervos olfativos. ${ }^{6}$ Curiosamente, a hiposmia é descrita como uma manifestação frequente na infeção pelo SARS-CoV-2, em muitos casos a manifestação inicial ou isolada da doença, o que sugere que o nervo olfativo pode ser uma via de acesso ao SNC por este novo coronavírus.

Não há qualquer evidência da implicação direta da infeção viral na evolução da DP ou de outras doenças do movimento, mas a questão da hiposmia associada ao COVID-I 9 tem suscitado hipóteses interessantes.

A hiposmia é um sintoma precoce em várias doenças neurodegenerativas, nomeadamente na DP. Uma das teorias patogénicas na DP sugere que a $\alpha$-sinucleína mutada se propaga através do bulbo olfativo por um mecanismo 'priónico', até atingir o tronco cerebral, justificando o aparecimento de hiposmia muitos anos antes dos primeiros sintomas motores. ${ }^{7}$

Outros vírus, com os quais os coronavírus têm alguma homologia, também conseguem invadir o SNC através da transmissão sináptica por nervos periféricos, nomeadamente através do nervo vago, até ao núcleo ambíguo e ao núcleo do trato solitário, no tronco cerebral, ${ }^{8}$ mais uma vez simulando o trajeto da $\alpha$-sinucleína anormal desde o intestino até ao tronco cerebral, segundo o eixo microbiota-intestino/cérebro descrito na DP.

O paralelismo entre estes sintomas e vias de invasão do SNC e o facto de se ter demonstrado que a $\alpha$-sinucleína participa na resposta imunitária inata às infeções virais, tem gerado alguma preocupação, receando-se que a infeção pelo SARS-CoV-2 possa constituir um trigger para as alterações conformacionais da $\alpha$-sinucleína e dar início à formação de agregados proteicos. ${ }^{7}$

\section{Efeitos Indiretos do SARS-CoV-2}

Não são de forma alguma desprezíveis os efeitos do confinamento imposto às classes etárias mais avançadas como medida de mitigação da pandemia. A incapacidade dos doentes com DP manterem exercício físico e/ ou reabilitação física regulares acarreta um agravamento dos sintomas motores. A diminuição da atividade física, o medo, o isolamento social e o distanciamento da família associados a uma menor capacidade adaptativa bem conhecida na DP, potenciam e perpetuam quadros de ansiedade, que como se sabe agravam os sintomas motores (como tremor, freezing, discinesias) e reduzem a eficácia da medicação dopaminérgica. ${ }^{9}$

O facto de todo o sistema de saúde, no cumprimento das regras do estado de emergência, ter reduzido substancialmente a atividade assistencial de ambulatório, veio gerar ainda mais dificuldades aos doentes com doenças como a DP. A esta situação juntam-se o receio de haver irregularidade na distribuição e no acesso a medicamentos e, para alguns, os potenciais efeitos nefastos da interrupção dos ensaios clínicos. ${ }^{10}$

Conselhos e medidas preventivas para os doentes com DP no contexto de pandemia COVID-19

Neste cenário, a prioridade deve centrar-se na proteção dos doentes. Sugerem-se orientações simples (Tabela 1), que pretendem dar resposta a questões colocadas pelos doentes/cuidadores e que podem ser de- 
Tabela 1. Conselhos e medidas preventivas para os doentes com DP em contexto da pandemia COVID-19.

1. Tentar garantir o cumprimento estrito das regras vigentes sobre isolamento/distanciamento social (do doente e dos cuidadores).

2. Prestar informação sobre o COVID-19

- É importante limitar a informação a fontes credíveis e pouco tempo por dia. O excesso de informação é muitas vezes confundidor e uma fonte de ansiedade.

- Adaptar as medidas preventivas às necessidades regionais, permitindo um alívio das medidas de isolamento em regiões com atividade residual da doença.

3. Ajudar a desenvolver estratégias para mitigar o isolamento

- Manter as rotinas diárias: despertar, hábitos de higiene, vestir, horas das refeições, horários da medicação e hora de ir para a cama.

- Manter contacto regular não presencial com familiares, amigos e vizinhos

- Participar em fóruns online de doentes/cuidadores que vivam o mesmo tipo de dificuldades

- Garantir apoio para as atividades essenciais: higiene, alimentação e tarefas domésticas

- Recorrer, se necessário, a linhas telefónicas de apoio psicológico.

4. Implementar programas para preservação do bem-estar físico e mental.

- Realizar caminhadas no espaço exterior, quando possível (mantendo as regras do distanciamento social, nomeadamente uso de máscara e/ou viseira).

- Manter atividade física com exercícios simples ou preferencialmente com programa orientado por fisiatra/ fisioterapeuta - por telefone ou seguindo programas disponíveis na Internet.

- Integrar no dia-a-dia atividades de carácter lúdico (ex. leitura, pintura, escrita, ver filmes, palavras cruzadas, sudoku, trabalhos manuais).

- Estabelecer um programa de atividades para a semana.

- Sugerir outras técnicas de relaxamento (ex. yoga, mindfulness).

- Retomar atividades de fisioterapia, exercício em ginásio logo que possível, uma vez garantidas as medidas de segurança.

5. Manter acompanhamento médico com o neurologista assistente recorrendo, se necessário, a telemedicina (vídeoconsulta, teleconsulta).

6. Se houver necessidade de assistência hospitalar, preparar informação sobre a doença, incluindo todas a medicação anti-parkinsónica em curso.

terminantes para evitar o risco de infeção e para manter o bem-estar físico e mental. Estas orientações estão de acordo com as recomendações da International Parkinson and Movement Disorder Society.

As medidas mais restritivas espelhavam as necessidades em estado de emergência. Após o estado de emergência e durante as fases sucessivas de desconfinamento, as restrições sugeridas tendem a ser atenuadas, tornando-se mais fácil o acesso aos serviços de saúde. $A$ atenuação das medidas poderá ter que ser regionalmente adaptada, dependendo da localização geográfica dos focos mais ativos da doença.

\section{Responsabilidades Éticas}

Conflitos de Interesse: Os autores declaram não possuir conflitos de interesse.

Suporte Financeiro: O presente trabalho não foi suportado por nenhum subsidio o bolsa ou bolsa.

Proveniência e Revisão por Pares: Não comissionado; revisão externa por pares.

\section{Ethical Disclosures}

Conflicts of interest: The authors have no conflicts of interest to declare.

Financial Support: This work has not received any contribution grant or scholarship.

Provenance and Peer Review: Not commissioned; externally peer reviewed.

\section{Referências}

1. Chen T, Wu D, Chen H, Yan W, Yang D, Chen G, et al. Clinical characteristics of 113 deceased patients with coronavirus disease 2019 : retrospective study. BMJ. 2020;368:m1091. doi: 10.1136/bmj.m1091.

2. Tipton PW, Wszolek ZK. What can Parkinson's disease teach us about COVID-19? Neurol Neurochir Pol. 2020;54:204-6. doi: 10.5603/PJNNS.a2020.0039.

3. Brison E, Jacomy H, Desforges M, Talbot PJ. Novel treatment with neuroprotective and antiviral properties against a neuroinvasive human respiratory virus. J Virol. 2014;88:1548-63. doi: 10.1128/JVI.02972-13.

4. Cunnington A, Hood K, White L. Parkinsonism and Related Disorders Outcomes of screening Parkinson 's patients for QTc prolongation. Parkinsonism Relat Disord. 2013;19:1000-3. doi: 10.1016/j.parkreldis.2013.07.001.

5. Mao L, Wang M, Chen S, He Q, Chang J. Neurological Manifestations of Hospitalized Patients with COVID-19 in Wuhan, China: a retrospective case series study. JAMA 
Neurol. 2020 ;77:1-9. doi: 10.1001/jamaneurol.2020.1127.

6. Li YC, Bai W, Hashikawa T. The neuroinvasive potential of SARS CoV2 may play a role in the respiratory failure of COVID 19 patients. J Med Virol. 2020;92:552-5. doi: 10.1002/jmv.25728.

7. Rey NL, Wesson DW, Brundin P. The olfactory bulb as the entry site for prion-like propagation in neurodegenerative diseases. Neurobiol Dis. 2018;109:226-48. doi: 10.1016/j. nbd.2016.12.013.

8. Matsuda K, Park C, Sunden Y, Kimura T, Ochiai K, Kida H, et al. The vagus nerve is one route of transneural invasion for intranasally inoculated influenza a virus in mice. Vet Pathol. 2004;41:101-7. doi: 10.1354/vp.41-2-101.

9. Helmich RC, Bloem BR. The impact of the COVID-19 pandemic on Parkinson's disease: hidden sorrows and emerging opportunities. J Parkinsons Dis. 2020;10:351-4. doi: 10.3233/JPD-202038.

10. Papa SM, Brundin P, Fung VSC, Kang UJ. Impact of the COVID-19 pandemic on Parkinson 's disease and movement disorders. Mov Disord. 2020 ;35:711-5. doi: 10.1002/ mds.28067. 